\title{
Pyoderma gangrenosum after trauma in a dog
}

\author{
Noriyuki NAGATA ${ }^{1)}$, Masashi YUKI ${ }^{1,2) *}$, Ryota ASAHINA ${ }^{2)}$, Hiroki SAKAI ${ }^{2)}$ and Sadatoshi MAEDA ${ }^{2)}$ \\ 1) Yuki Animal Hospital, 2-99 Kiba-cho, Minato-ku, Nagoya, Aichi 455-0021, Japan \\ ${ }^{2)}$ Department of Veterinary Medicine, Faculty of Applied Biological Sciences, Gifu University, 1-1 Yanagido, Gifu 501-1193, Japan
}

(Received 27 December 2015/Accepted 9 April 2016/Published online in J-STAGE 22 April 2016)

ABSTRACT. A 12-year-old male entire Miniature Pinscher presented with excoriations at various body sites, progressively forming ulcers and enlarging until arrested by treatment. Based on the clinical presentation and histopathological analyses, sterile neutrophilic dermatosis was suspected. Therefore, the dog was started on prednisolone. Marked improvement was achieved with prednisolone treatment, suggesting a diagnosis of pyoderma gangrenosum (PG). Transcription levels of cytokine mRNA in lesional skin before and after treatment from this dog were quantified by real-time RT-PCR. Transcription levels of tumor necrosis factor- $\alpha$, interleukin (IL)-1 $\beta$, IL-8 and IL-17A were higher in lesional skin before treatment than after treatment. Levels of various cytokines could be increased in lesional skin of dogs with PG as well as in human patients with PG.

KEY WORDS: canine, pathergy, pyoderma gangrenosum, trauma

doi: 10.1292/jvms.15-0724; J. Vet. Med. Sci. 78(8): 1333-1337, 2016

Pyoderma gangrenosum (PG) is a rare, ulcerative, neutrophilic dermatosis in humans [1]. Although the disease is idiopathic in some patients, the high frequency of other immune-mediated comorbidities supports an immune-mediated pathogenesis for this disease [3]. In addition, the phenomenon of pathergy is reported in about $30 \%$ of human patients with PG [3]. Pathergy is defined as the onset of skin lesions at the site of trauma, such as cuts, needlestick injuries or surgery [5]. This phenomenon, is thought to reflect abnormal neutrophil function [4], and is one of the criteria for the diagnosis of Behçet's disease (the pathergy test) [7].

PG is likewise uncommon in dogs, with only two previous reports. One described development of PG after the diagnosis of non-erosive idiopathic polyarthritis [2], while the other noted two cases of PG with no apparent underlying disorder [17]. Little information has been accumulated regarding the characteristics of PG in dogs; therefore, consensus about treatment for this disease is lacking.

We describe the case of a dog that developed PG after trauma in which pathergy was suspected, with a good response to medical treatment with prednisolone alone. Moreover, we evaluated transcription levels of cytokine mRNA in lesional skin before and after treatment from this dog.

A 12-year-old male entire Miniature Pinscher was brought in to a night-time animal first-aid center with lethargy after being entrusted to a boarding kennel for 9 days. The dog was treated for dehydration, hypothermia $\left(36.6^{\circ} \mathrm{C}\right)$ and hypoglycemia. The dog was then brought to our hospital the following day (day 1), upon which physical examination revealed

*Correspondence to: Masashi, Y., Yuki Animal Hospital, 2-99 Kiba-cho, Minato-ku, Nagoya, Aichi 455-0021, Japan. e-mail: yuki-masashi@mvf.biglobe.ne.jp

(C)2016 The Japanese Society of Veterinary Science

This is an open-access article distributed under the terms of the Creative Commons Attribution Non-Commercial No Derivatives (by-nc-nd) License $<$ http://creativecommons.org/licenses/by-nc-nd/4.0/>. excoriation at various body sites, including the right eyelid, pinnae, neck and extremities. Swelling of the right eyelid was also evident (Fig. 1A). Body temperature was $39.3^{\circ} \mathrm{C}$. The owner and staff at the boarding kennel could not explain the cause of skin lesions, but no external factors, such as heat burn, cold exposure and chemical reaction, were reported. Previous medical histories of this dog included intermittent corticosteroids as prescribed by other facilities for pruritus by suspected allergic dermatitis.

A complete blood count showed neutrophilia $(26,200 / \mu l$, reference range 3,000-11,500/ $\mu l$ ). Laboratory data indicated increased C-reactive protein concentration (CRP; $7.0 \mathrm{mg}$ / $\mathrm{d} l$, reference range $0-0.9 \mathrm{mg} / \mathrm{d} l$ ). Urinalysis, thoracic and abdominal radiography, and abdominal ultrasonography revealed unremarkable findings.

Although the causes of lethargy and skin lesions were unknown, the dog was hospitalized with supportive therapy. In addition to intravenous fluid infusion with acetate Ringer's solution (Solacet; Terumo, Tokyo, Japan) and maintenance fluid (Soldem 3A; Terumo), it was initiated oral cephalexin (Larixin; Toyama Chemical, Tokyo, Japan) at $20 \mathrm{mg} / \mathrm{kg}$ twice daily for 21 days, enrofloxacin (Baytril; Bayer, Tokyo, Japan) at $7 \mathrm{mg} / \mathrm{kg}$ once daily for 21 days and firocoxib (Previcox; Merial, Tokyo, Japan) at $10 \mathrm{mg} / \mathrm{kg}$ once daily for potential bacterial infection and inflammation. Four days after initial presentation, the condition and blood abnormalities of the dog had improved; the dog was therefore discharged.

On day 9, the dog was brought back due to skin lesions with erosion on the right eyelid and cutaneous ulcers with necrotic eschar on the pinnae, neck and extremities. Cytology of a lesion showed sterile suppurative inflammation. Over the next several days, skin lesions progressively enlarged, and CRP again increased $(8.7 \mathrm{mg} / \mathrm{d} l)$. Endocrine testing including thyroid function test and adrenocorticotropic hormone-stimulation test was within reference ranges. Antinuclear antibody test was also negative. On day 13, skin biopsies were performed (Fig. 1B). Histopathological 

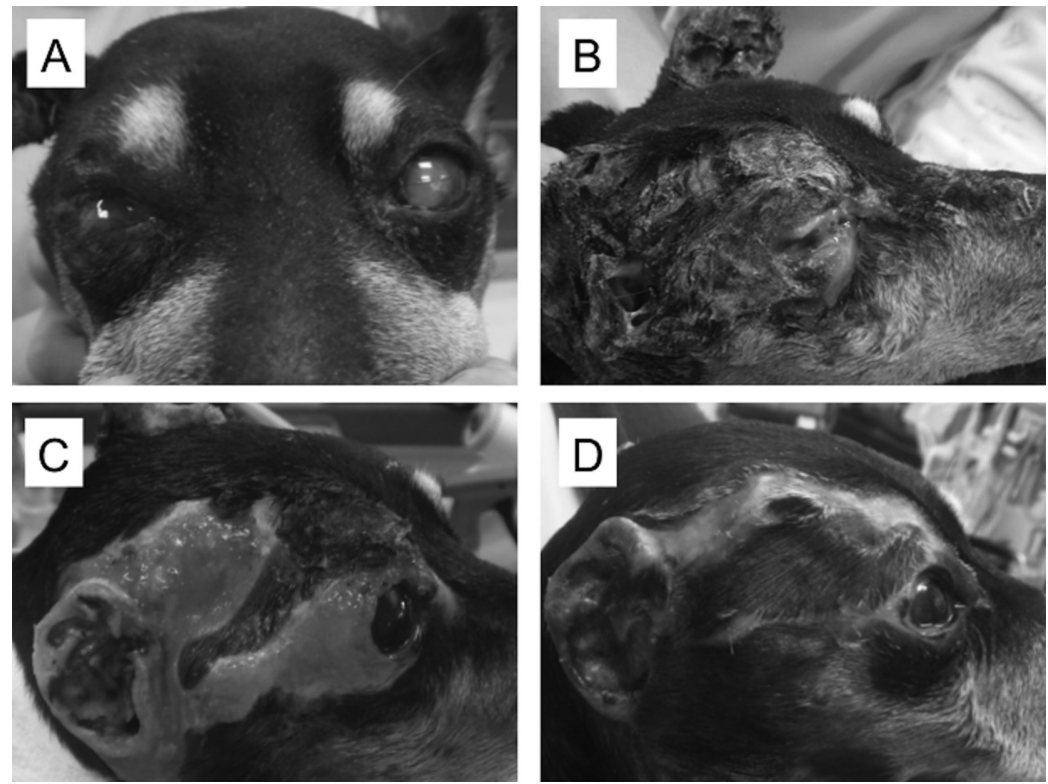

Fig. 1. (A) Photograph of the face of the dog on day 1, showing excoriation of right eyelid accompanied by swelling. (B) Photograph of the face on day 13, showing cutaneous ulcers with necrotic eschar on the right eyelid and pinnae. (C) Photograph of the face on day 21 with desquamation of necrotic skin. (D) Photograph of the face on day 49, showing almost complete resolution of skin lesions.

examination revealed necrosis of the epidermis, dermis and follicles, and moderate to marked neutrophilic infiltration of ulcer sites, perivascular and muscular layers, with no microorganisms, vasculitis, neoplasia or thrombus (Fig. 2). No infectious agents were identified using specific stains, such as periodic acid-Schiff, Ziehl-Neelsen, Grocott or Gram staining. Firocoxib was then replaced with prednisolone (Predonine; Shionogi, Osaka, Japan) at $1 \mathrm{mg} / \mathrm{kg}$ twice daily on the basis of suspected sterile neutrophilic dermatosis. On day 21, desquamation of necrotic skin was seen (Fig. 1C) along with decreased CRP $(<0.9 \mathrm{mg} / \mathrm{d} l)$, and cephalexin and enrofloxacin were terminated. On day 49, skin lesions had almost completely resolved (Fig. 1D). Prednisolone dose was tapered over 4 months and then terminated, and no recurrence has since been identified. This case was diagnosed as PG based on the proposed diagnostic criteria for human $\mathrm{PG}$, which require the satisfaction of two major criteria (including rapid progression of a painful, necrolytic cutaneous ulcer with an irregular, violaceous and undermined border, and exclusion of other causes of cutaneous ulceration) and at least two minor criteria, including (a) a history suggestive of pathergy or a clinical finding of cribriform scarring, (b) systemic diseases associated with PG, (c) histopathologic findings (sterile dermal neutrophilia \pm mixed inflammation \pm lymphocytic vasculitis) or (d) treatment response (rapid response to systemic steroid treatment) [18]. This case fulfilled many of the criteria, including progressive necrolytic ulcerations, exclusion of other causes of ulceration such as infection, vasculitis, neoplasia or thrombus, a history suggestive of pathergy, histologic findings of sterile dermal

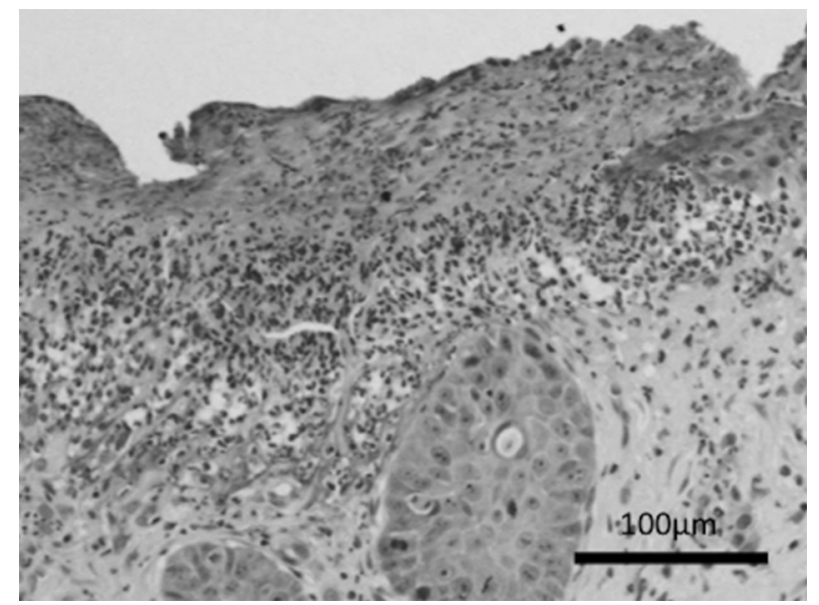

Fig. 2. Photomicrograph of a skin section with moderate to marked neutrophilic infiltration of ulcer site. Hematoxylin and eosin stain.

neutrophilia and rapid response to systemic corticosteroids.

A pair of skin biopsy samples was obtained from lesional skin before (day 13) and after (day 59) treatment. The sample of skin after treatment was obtained from the scar at the site of lesional skin. All skin samples were immediately submerged in RNA later (Qiagen, Valencia, CA, U.S.A.) and stored at $-20^{\circ} \mathrm{C}$ for 117 days (skin before treatment) and for 71 days (skin after treatment) until the extraction of total RNA using an RNeasy Plus Mini Kit (Qiagen). Genomic 
Table 1. Sequences of primers for quantitative real-time RT-PCR

\begin{tabular}{lll}
\hline Target gene & \multicolumn{1}{c}{ Forward primer $\left(5^{\prime}-3^{\prime}\right)$} & \multicolumn{1}{c}{ Reverse primer $\left(5^{\prime}-3^{\prime}\right)$} \\
\hline TNF- $\alpha$ & CCCAAGTGACAAGCCAGTAGCTC & ACAACCCATCTGACGGCACTATC \\
IL-1 $\beta$ & ACCCGAACTCACCAGTGAAATG & GGTTCAGGTCTTGGCAGCAG \\
IL-8 & CTTCCAAGCTGGCTGTTGCTC & TGGGCCACTGTCAATCACTCTC \\
IL-17A & CTCCAGAAGGCCCTCAGATTAC & CTTCGCCTCCCAGATCACA \\
CG14980 & GCAGGAAGGGATTCTCCAG & GGTCCAGTAAGAAATCTTCCATAA \\
SDHA & GCCTTGGATCTCTTGATGGA & TTCTTGGCTCTTATGCGATG \\
TBP & CTATTTCTTGGTGTGCATGAGG & CCTCGGCATTCAGTCTTTTC \\
\hline
\end{tabular}

TNF tumor necrosis factor, IL interleukin.
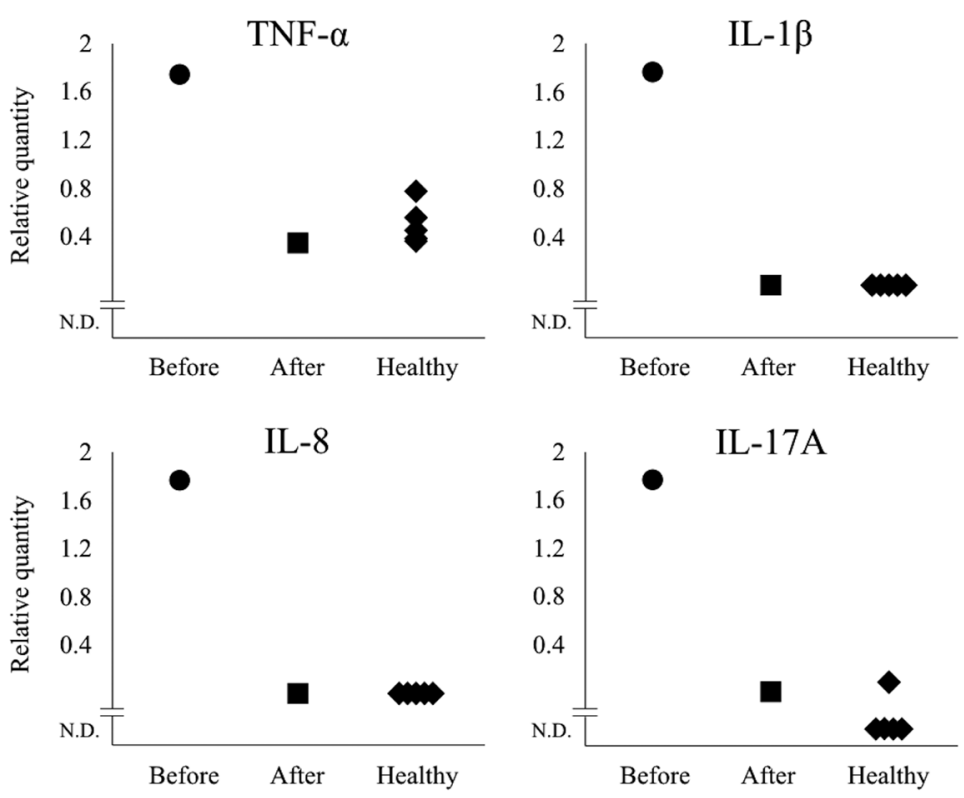

Fig. 3. Relative transcription levels of cytokine mRNA in lesional skin before treatment (Before), skin after treatment (After) and normal skin of healthy dogs (Healthy, $n=5$ ). Transcription levels of tumor necrosis factor (TNF)- $\alpha$ and interleukin (IL)-1 $\beta$, IL-8 and IL-17A were higher in lesional skin before treatment than in skin after treatment or normal skin of healthy dogs. N.D.: not detected.

DNA was removed from samples with a TURBO DNA-free Kit (Applied Biosystems, Foster City, CA, U.S.A.) and then stored at $-80^{\circ} \mathrm{C}$ for a day. Transcription of cytokine mRNA was quantified by two-step RT-PCR using a Thermal Cycler Dice $^{\circledR}$ Real Time System TP800 (Takara Bio, Otsu, Japan) as described previously [6]. Total RNA $(0.5 \mu \mathrm{g})$ was reversetranscribed to cDNA using a PrimeScript ${ }^{\mathrm{TM}}$ RT Reagent Kit (Takara Bio). Quantitative real-time RT-PCR was performed using a SYBR ${ }^{\circledR}$ Premix Ex Taq ${ }^{\mathrm{TM}}$ II system (Takara Bio). CT (threshold cycle) values were determined using Thermal Cycler Dice Real Time System Multiplate RQ version 2.00 software (Takara Bio). All samples were examined in duplicate, and the mean value of $\triangle \mathrm{CT}$ was calculated. Amounts of each mRNA transcription level (relative quantity) were calculated using 2- $\Delta \mathrm{CT}$, resulting in evaluation of samples as $n$-fold differences relative to that of the mean value of three reference genes. Primer pairs used in this dog are listed in Table 1. Primers for canine tumor necrosis factor (TNF)- $\alpha$, interleukin (IL)- $1 \beta$ and IL- 8 were designed by a contact manufacturing service (Takara Bio). Primers for canine IL-17A were designed using the freely available Primer 3 software (http://www.genome.wi.mit.edu/genome_software/other/primer3.html). The specificities of these primers were confirmed to amplify each target mRNA by sequential analysis of the PCR products using ABI Prism 3100 Genetic Analyzer (Applied Biosystems). For accurate quantification, three reference genes (CG14980, SDHA and TBP) were chosen (Table 1).

Figure 3 shows the relative quantities of each gene examined in this case and normal skin of healthy dogs $(n=5)$. TNF- $\alpha$, IL-1 $\beta$, IL- 8 and IL-17A were selected for analysis, because overexpression of these cytokines had been shown in human PG $[8,9]$. Transcription levels of TNF- $\alpha$, IL-1 $\beta$, IL-8 and IL-17A, were higher in lesional skin before treat- 
Table 2. Characteristics of the present case, erythema multiforme, toxic epidermal necrolysis and vasculitis

\begin{tabular}{|c|c|c|c|c|c|c|}
\hline & Cause & $\begin{array}{r}\text { Types of } \\
\text { eruptions }\end{array}$ & $\begin{array}{l}\text { Distributions } \\
\text { of eruptions }\end{array}$ & $\begin{array}{l}\text { Types of inflammatory } \\
\text { cells (histopathology) }\end{array}$ & $\begin{array}{c}\text { Use of } \\
\text { glucocorticoids }\end{array}$ & Prognosis \\
\hline $\begin{array}{l}\text { The present } \\
\text { case }\end{array}$ & $\begin{array}{l}\text { Unknown } \\
\text { (suspected pathergy) }\end{array}$ & $\begin{array}{l}\text { Excoriation, } \\
\text { erosion, ulcer }\end{array}$ & $\begin{array}{l}\text { Eyelid, pinnae, } \\
\text { neck, extremities }\end{array}$ & $\begin{array}{l}\text { Neutrophils (invasion of } \\
\text { ulcer sites, perivasucular } \\
\text { and muscular layers) }\end{array}$ & $\begin{array}{l}\text { Effective } \\
\text { (monotherapy) }\end{array}$ & $\begin{array}{l}\text { Good (with no } \\
\text { reccurence) }\end{array}$ \\
\hline $\begin{array}{l}\text { Erythema } \\
\text { multiforme }\end{array}$ & $\begin{array}{l}\text { Drug reactions } \\
(19-59 \%), \\
\text { idiopathy, infections, } \\
\text { food, neoplasia }\end{array}$ & $\begin{array}{l}\text { Erythematous } \\
\text { macule, papule, } \\
\text { urticarial plaque, } \\
\text { vesicle, bulla, } \\
\text { ulcer }\end{array}$ & $\begin{array}{l}\text { Ventrum, } \\
\text { mucocutaneous } \\
\text { junctions, oral } \\
\text { cavity, pinnae, } \\
\text { footpads }\end{array}$ & Lymphocytes & $\begin{array}{l}\text { Possibly effective } \\
\text { (in idiopathic, } \\
\text { refractory, or severe } \\
\text { cases) }\end{array}$ & $\begin{array}{l}\text { Relatively good } \\
\text { (regressing } \\
\text { by eliminating } \\
\text { trigger factors } \\
\text { in most cases) }\end{array}$ \\
\hline $\begin{array}{l}\text { Toxic } \\
\text { epidermal } \\
\text { necrolysis }\end{array}$ & $\begin{array}{l}\text { Drug reactions } \\
\text { (majority), vaccine } \\
\text { reactions, } \\
\text { neoplasia, infections, } \\
\text { pregnancy }\end{array}$ & $\begin{array}{l}\text { Erythematous } \\
\text { macule, vesicle, } \\
\text { bulla, ulcer }\end{array}$ & $\begin{array}{l}\text { Body, mucosa } \\
\text { (anywhere) }\end{array}$ & $\begin{array}{l}\text { Lymphocytes (minimal } \\
\text { inflammation) }\end{array}$ & Controversial & $\begin{array}{l}\text { Guarded to poor } \\
\text { (no published } \\
\text { mortality rate) }\end{array}$ \\
\hline Vasculitis & $\begin{array}{l}\text { Idiopathy }(50 \% \text { or } \\
\text { more), vaccine } \\
\text { reactions, drug } \\
\text { reactions, neoplasia, } \\
\text { infections, food }\end{array}$ & $\begin{array}{l}\text { Purpura, erythe- } \\
\text { ma, bulla, ulcer, } \\
\text { alopecia, wheal, } \\
\text { papule, pustule }\end{array}$ & $\begin{array}{l}\text { Pinnae and/or } \\
\text { footpads (most } \\
\text { common), paws, } \\
\text { claws, lower legs, } \\
\text { lips, tail, scrotum, } \\
\text { oral mucosa }\end{array}$ & $\begin{array}{l}\text { Neutrophils, eosinophils, } \\
\text { mononuclear cells (inva- } \\
\text { sion of vessel walls) }\end{array}$ & $\begin{array}{l}\text { Possibly effective } \\
\text { (mostly with other } \\
\text { drugs such as } \\
\text { pentoxifylline, } \\
\text { sulfasalazine and } \\
\text { dapsone) }\end{array}$ & $\begin{array}{l}\text { Relatively high } \\
\text { recurrence rate }\end{array}$ \\
\hline
\end{tabular}

Modified from Miller, W. H. Jr, Griffin, C. E. and Campbell, K. L. 2013. Autoimmune and immune-mediated dermatoses. pp. 432-500. In: Muller and Kirk's Small Animal Dermatology, 7th ed. (Miller, W. H. Jr, Griffin, C. E. and Campbell, K. L. eds.), Elsevier, St. Louis., Scott, D. W. and Miller, W. H. 1999. Erythema multiforme in dogs and cats: literature review and case material from the Cornell University College of Veterinary Medicine (1988-96). Vet. Dermatol. 10: 297-309., and Nichols, P. R., Morris, D. O. and Beale, K. M. 2001. A retrospective study of canine and feline cutaneous vasculitis. Vet. Dermatol. 12: 255-264.

ment than in skin after treatment or normal skin of healthy dogs.

Typically, lesions of human PG manifest most commonly on the lower extremities, as well as on the trunk, upper extremities, head and neck [3]. Primary lesions in humans are shown as painful nodules or pustules, either single or multiple, that evolve to superficial ulcers, often extending into the fat and fascia [15]. Primary lesions of three dogs in past reports have included facial swelling with ulcers on the muzzle [2], pustules and erosions on the body [17], and an ulcer and subcutaneous nodules on the neck and trunk [17]. Some differences are evident in the site of primary lesions between human PG and previously reported cases in dogs, with lesions of the lower extremities (hindlimbs) being uncommon in dogs, while lesions of the face were recognized in all dogs during the course of diseases [2, 17], as well as our case. In our case, skin lesions at multiple sites were excoriations rapidly turned into ulcers that progressively enlarged. The cause of the initial skin lesions is unclear, but the dog might have suffered trauma while in the kennel that might have caused the phenomenon of pathergy, although this possibility remains purely speculative. A history suggestive of pathergy, indicated as development of new lesions at the site of trauma, is included in the minor diagnostic criteria for PG [18].

Differential diagnoses for human PG may include vasculitis, malignancy, primary cutaneous infection, drug-induced or exogenous tissue injury [18]. Although diagnostic criteria have been proposed for human PG [18], none have been formally adopted $[1,5]$. The diagnosis therefore remains primarily based on clinical features and exclusion [1]. Biopsy is mainly conducted to exclude other potential causes of ulceration, because of the non-specific histopathologic findings [15]. On the other hand, neutrophils can provide a cytologic hallmark of human PG [15]. Drug eruptions are suggested to most generally develop within $1-3$ weeks of the initiation of treatment [10]. For this reason, drug eruptions could be possible, because this dog had received pharmacotherapy from initial presentation, including cephalexin, enrofloxacin and firocoxib, which could potentially induce drug hypersensitivity $[10,19]$. The lesions had worsened on day 9. Of these drugs, cephalexin and enrofloxacin could result in erythema multiforme and toxic epidermal necrolysis as potential causes of skin necrosis and ulceration [10]. However, drug hypersensitivity with cephalexin and enrofloxacin was ruled out, because of the continued prescription after amelioration. In addition, these cutaneous drug eruptions were also excluded based on the histopathological findings. Although skin biopsy in our case was conducted on day 13, which might have missed some findings, such as vasculitis, that could have existed at initial presentation, vasculitis was principally ruled out in this case based on the histopathology and clinical characteristics. The characteristics of the present case are compared with those of erythema multiforme, toxic epidermal necrolysis and vasculitis in Table $2[10,11,16]$.

Immunosuppressive treatment with systemic corticosteroids and cyclosporine is considered to be the first-line therapy for this disease $[13,14]$. In dogs, the few reports describing treatment for PG have included corticosteroid with cyclosporine $[2,17]$ and corticosteroid with azathioprine [17], with good initial response. Prednisone or prednisolone was prescribed to these dogs at initial doses of $0.75-1.0 \mathrm{mg} /$ 
$\mathrm{kg}$ twice daily, and no side effects were reported $[2,17]$. In our case, prednisolone alone at an initial dose of $1.0 \mathrm{mg} / \mathrm{kg}$ twice daily was commenced to treat PG, achieving marked improvements without visible side effects. In a review of 24 PG cases in humans, 10 cases were treated using only corticosteroids [13]. The present case indicates that dogs with PG could be treated with corticosteroids alone, as in humans.

Pyoderma gangrenosum is classified within the group of neutrophilic dermatoses, however, pathophysiological and molecular characteristics remain largely unknown [4]. In humans, expression of cytokines, such as TNF- $\alpha$, IL- $1 \beta$, IL-8 and IL-17 (measured by immunohistochemistry or sandwich-based protein antibody array), was significantly higher in lesional skin of patients with PG than in normal controls $[8,9]$. IL-8, a well-known chemotactic polypeptide for neutrophils, has been detected in dermal fibroblasts from ulcer sites of human PG, indicating that IL-8 plays an important role in the pathogenesis [12]. Moreover, overexpression of TNF- $\alpha$ at the lesion site during human PG indicates that TNF- $\alpha$ also has a significant role in the immunopathogenesis $[8,9]$. This provides a principle for the use of anti-TNF- $\alpha$ drugs in human PG $[1,8,9]$. Other cytokines, such as IL-1 $\beta$ and IL-17, are also overexpressed in human PG and other neutrophilic dermatoses like Sweet's syndrome, suggesting a potential role for the pathophysiology of the group of neutrophilic dermatoses $[8,9]$. In our case, transcription levels of IL-1 $\beta$, IL- 8 , TNF- $\alpha$ and IL-17A were all higher in lesional skin before treatment than in skin after treatment or normal skin of healthy dogs, implying that these cytokines were associated with the development of lesions in this dog, as in human PG $[8,9]$. These results indicate that pathophysiological and molecular characteristics of canine PG might be similar with those of human PG, but further studies are needed to evaluate cytokine expression profiles in more cases.

\section{REFERENCES}

1. Ahronowitz, I., Harp, J. and Shinkai, K. 2012. Etiology and management of pyoderma gangrenosum: a comprehensive review. Am. J. Clin. Dermatol. 13: 191-211. [Medline] [CrossRef]

2. Bardagí, M., Lloret, A., Fondati, A. and Ferrer, L. 2007. Neutrophilic dermatosis resembling pyoderma gangrenosum in a dog with polyarthritis. J. Small Anim. Pract. 48: 229-232. [Medline] [CrossRef]

3. Binus, A. M., Qureshi, A. A., Li, V. W. and Winterfield, L. S. 2011. Pyoderma gangrenosum: a retrospective review of patient characteristics, comorbidities and therapy in 103 patients. $\mathrm{Br} . J$. Dermatol. 165: 1244-1250. [Medline] [CrossRef]

4. Braswell, S. F., Kostopoulos, T. C. and Ortega-Loayza, A. G. 2015. Pathophysiology of pyoderma gangrenosum (PG): an updated review. J. Am. Acad. Dermatol. 73: 691-698. [Medline] [CrossRef]

5. Callen, J. P. and Jackson, J. M. 2007. Pyoderma gangrenosum: an update. Rheum. Dis. Clin. North Am. 33: 787-802, vi. [Medline] [CrossRef]

6. Chimura, N., Kondo, N., Shibata, S., Kimura, T., Mori, T., Hoshino, Y., Murayama, N., Nagata, M., Ide, K., Nishifuji, K.,
Kamishina, H. and Maeda, S. 2011. Gene transcription analysis in lesional skin of canine epitheliotropic cutaneous lymphoma using quantitative real-time RT-PCR. Vet. Immunol. Immunopathol. 144: 329-336. [Medline] [CrossRef]

7. International Team for the Revision of the International Criteria for Behçet's Disease (ITR-ICBD) 2014. The International Criteria for Behçet's Disease (ICBD): a collaborative study of 27 countries on the sensitivity and specificity of the new criteria. $J$. Eur. Acad. Dermatol. Venereol. 28: 338-347. [Medline] [CrossRef]

8. Marzano, A. V., Cugno, M., Trevisan, V., Fanoni, D., Venegoni, L., Berti, E. and Crosti, C. 2010. Role of inflammatory cells, cytokines and matrix metalloproteinases in neutrophil-mediated skin diseases. Clin. Exp. Immunol. 162: 100-107. [Medline] [CrossRef]

9. Marzano, A. V., Fanoni, D., Antiga, E., Quaglino, P., Caproni, M., Crosti, C., Meroni, P. L. and Cugno, M. 2014. Expression of cytokines, chemokines and other effector molecules in two prototypic autoinflammatory skin diseases, pyoderma gangrenosum and Sweet's syndrome. Clin. Exp. Immunol. 178: 48-56. [Medline] [CrossRef]

10. Miller, W. H. Jr., Griffin, C. E. and Campbell, K. L. 2013. Autoimmune and immune-mediated dermatoses. pp. 432-500. In: Muller and Kirk's Small Animal Dermatology, 7th ed. (Miller, W. H. Jr, Griffin, C. E. and Campbell, K. L. eds.), Elsevier, St. Louis.

11. Nichols, P. R., Morris, D. O. and Beale, K. M. 2001. A retrospective study of canine and feline cutaneous vasculitis. Vet. Dermatol. 12: 255-264. [Medline] [CrossRef]

12. Oka, M., Berking, C., Nesbit, M., Satyamoorthy, K., Schaider, H., Murphy, G., Ichihashi, M., Sauter, E. and Herlyn, M. 2000. Interleukin-8 overexpression is present in pyoderma gangrenosum ulcers and leads to ulcer formation in human skin xenografts. Lab. Invest. 80: 595-604. [Medline] [CrossRef]

13. Pereira, N., Brites, M. M., Gonçalo, M., Tellechea, O. and Figueiredo, A. 2013. Pyoderma gangrenosum - a review of 24 cases observed over 10 years. Int. J. Dermatol. 52: 938-945. [Medline] [CrossRef]

14. Reichrath, J., Bens, G., Bonowitz, A. and Tilgen, W. 2005. Treatment recommendations for pyoderma gangrenosum: an evidence-based review of the literature based on more than 350 patients. J. Am. Acad. Dermatol. 53: 273-283. [Medline] [CrossRef]

15. Ruocco, E., Sangiuliano, S., Gravina, A. G., Miranda, A. and Nicoletti, G. 2009. Pyoderma gangrenosum: an updated review. J. Eur. Acad. Dermatol. Venereol. 23: 1008-1017. [Medline] [CrossRef]

16. Scott, D. W. and Miller, W. H. 1999. Erythema multiforme in dogs and cats: literature review and case material from the Cornell University College of Veterinary Medicine (1988-96). Vet. Dermatol. 10: 297-309. [CrossRef]

17. Simpson, D. L., Burton, G. G. and Hambrook, L. E. 2013. Canine pyoderma gangrenosum: a case series of two dogs. Vet. Dermatol. 24: 552-e132. [Medline] [CrossRef]

18. Su, W. P. D., Davis, M. D. P., Weenig, R. H., Powell, F. C. and Perry, H. O. 2004. Pyoderma gangrenosum: clinicopathologic correlation and proposed diagnostic criteria. Int. J. Dermatol. 43: 790-800. [Medline] [CrossRef]

19. Voie, K. L., Campbell, K. L. and Lavergne, S. N. 2012. Drug hypersensitivity reactions targeting the skin in dogs and cats. $J$. Vet. Intern. Med. 26: 863-874. [Medline] [CrossRef] 